Journal Home Page:

http://perlinguam.journals.ac.za

\section{Per Linguam}

A Journal for Language Learning Tydskrif vir Taalaanleer

\title{
THE WRITE APPROACH: CAN R2L HELP AT TERTIARY LEVEL?
}

\author{
Rosemary Wildsmith-Cromarty \\ Kellie Steinke \\ University of KwaZulu-Natal
}

This article discusses a one-year intervention that was implemented using the Read to Learn (R2L) approach with 46 isiZulu-speaking students at a South African University in 2011. All the students were in the BCom 4 Access Programme at the University of KwaZulu-Natal and originated from Quintile 1-4 schools. Participating students were taught to understand and read selected texts. They were then assisted through a process of 'scaffolding', in which they ultimately learnt how to independently write a text of the same genre, using the six stages of the R2L teaching cycle. Of the original 46 students, 10 were closely tracked. Various data were collected and analysed during the study period. Findings revealed that there was a marked improvement in both reading (an increase of at least two levels) and writing abilities at both the micro and the macro levels of text. These results suggest that the R2L approach, as a reading intervention, can contribute towards the improvement of the academic literacy levels of disadvantaged students at tertiary level.

\section{Key Words}

Reading to learn, genre teaching, writing pedagogy, scaffolding reading, academic literacy

\section{INTRODUCTION}

Academic language skills are regarded as a primary indicator of academic success at tertiary level (Weideman \& Van Rensburg, 2002), yet the South African Education system continues to fail its children. Despite seventeen years of democracy, huge inequalities still exist between disadvantaged and advantaged communities in terms of teacher-training, teaching methods and physical resources. Only $7.2 \%$ of South African schools have functional libraries (Machet and Pretorius, 2008). In the Progress in International Reading Literacy Study (PIRLS) 2006, released in November 2007, South Africa came last out of 40 countries, achieving a score of only 302 points against an average of 500 (Howie et al., 2008: 1). The PIRLS Report for 2011 shows next to no change in the scores and averages (Howie et al., 2012). Coupled with a general lack of reading culture in poorer socio-economic communities (Ntuli and Pretorius, 2005) and the failure of Outcomes Based Education (Jansen, 1998), this presents a real challenge for developing academic literacy at tertiary level.

Lecturers who teach access students in the BCom4 programme have noticed that students entering the university are seriously underprepared for tertiary level study in terms of both general knowledge and academic literacy skills. This observation resonates with those of a number of other academic literacy specialists teaching at universities in South Africa (Boughey, 2008; Van Dyk, 2004; Weideman, 2003; Steinke, 2012). Although students 
generally have reasonable conversational skills, this can result in a lack of recognition of weakness in the area of the cognitive skills required for academic language proficiency (Cummins, 2000). Nthuli and Pretorius show a strong correlation between early print exposure and academic success (Ntuli and Pretorius, 2005), but students at tertiary level obviously cannot return to school to recoup their lack of academic literacy skills. Van der Slik and Weideman (2008), predict that the rate of academic literacy improvement is dependent upon the student's initial literacy level, and that students who enter a literacy programme with lower levels of literacy skills should show the greatest increases. Rose makes similar claims for R2L (Rose, 2006, Van der Slik and Weideman, 2008). The purpose of the current intervention, therefore, was to test the efficacy of the R2L approach at first-year tertiary level. One of the reasons for choosing Read to Learn (hereafter R2L) as an intervention was the fact that it is a theoretically justified approach which integrates all aspects of academic literacy in an implementation cycle, as outlined below. Although a number of researchers have contributed to both the theory and practice of academic literacy in various ways (Boughey, 2008; Weideman, 2003), our literature review did not render any other approach packaged in this way. Furthermore, the intention was to carefully monitor the implementation process in order to gauge the effects of the approach on the learners' reading skills and their subsequent ability to write and structure texts within an academic context. Written consent was obtained from all participants before the research project was undertaken and names of all students have been changed.

\section{THEORETICAL FRAMEWORK}

R2L is based on a theoretical framework which draws on both the Genre approach (Martin and Rose, 2005) and Systemic Functional Grammar (Halliday, 1994, Halliday, 1995). Whilst important research has been carried out in the area of Genre approaches and pedagogy in South Africa (Carstens, 2008, Klos, 2011), the main focus has been on writing. However, R2L, along with other reading interventions, highlights the importance of developing proficiency in reading as a pre-requisite for developing writing skills. Most universities in South Africa have Writing Centres in place to help struggling students with their assignments (Paxton et al., 2008; Weideman, 2009) but these may not reach their full level of effectiveness if they continue to operate on a 'drop-in' basis. R2L proceeds from the premise that the development of reading is a carefully scaffolded process and is the responsibility of every teacher in every discipline, i.e. that explicit teaching and scaffolding of reading should occur across the curriculum within specific disciplines and at every educational level. This, however, is the ideal. For the present, it normally falls to the lecturers responsible for developing academic literacy skills in their students either as language specialists working alongside subject area specialists in specific disciplines such as Health Sciences, Law, Theology or Science, or in 'stand-alone' courses. The focus of this article is on the latter.

Halliday connects Systemic Functional Grammar (SFG) to genre approaches (Halliday, 1994) because he believes literacy can only be understood in functional terms. Genre approaches, for Halliday, aim to increase the power of the student through literacy which enables them to take action and contribute, even in a small way, to influencing both politics and the economy. Such approaches do this by concentrating on textual access and on an increasing understanding of how mastery of linguistic structures and forms is necessary for access to political and economic power. Building on Bernstein's concern with the 'hidden curriculum' 
(Bernstein, 1990, 2000), Vygotsky's 'Zone of Proximal Development' (Vygotsky, 1978) and the concept of 'Scaffolding' (Bruner, 1957), the Genre approach uses a 'visible pedagogy' that makes explicit the linguistic structures necessary to achieve equality. It achieves this by use of a three-stage teaching cycle:

- $\quad$ Preparation before reading, in which students are orientated to the genre and field of the text. In this stage, the text is deconstructed.

- Group rewrite, where students use notes to rewrite the same text, guided by the teacher. In this stage, the text is reconstructed.

- $\quad$ An independent writing task, where students use a text of the same genre to write their own text. This is the task on which students are assessed.

Diagram 1 below illustrates the cyclical nature of the process (Rose, 2009):

\section{Diagram 1: The Genre Approach Teaching Cycle}

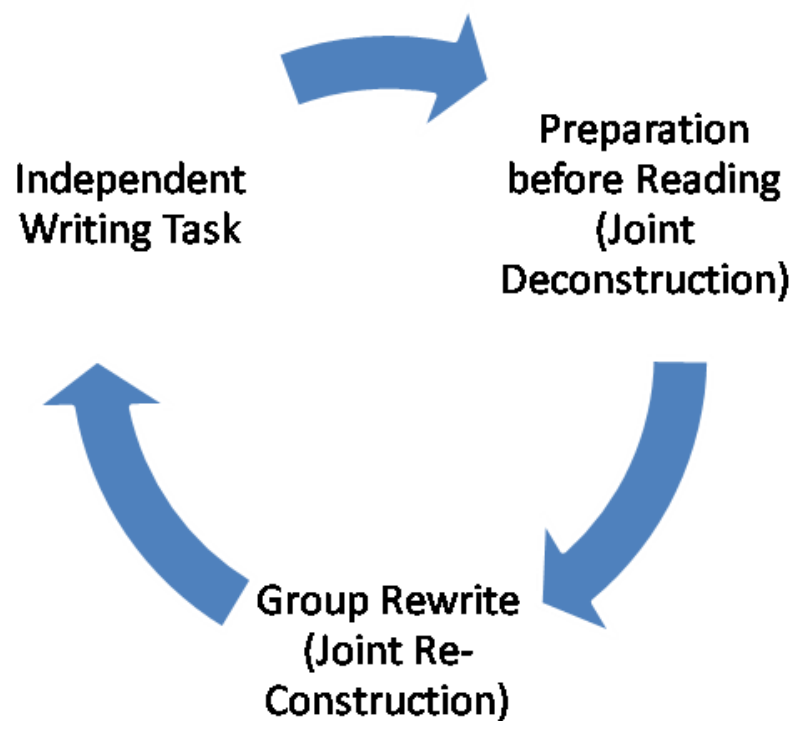

In order to facilitate reading, Rose $(2005 ; 2009)$ added three extra cycles to those already existing in the genre approach. These are:

- Detailed reading, in which the teacher supports the students' reading of each sentence by using preparation cues. Students underline these cues in the text.

- $\quad$ Preparing for writing by note taking, in which the students take turns acting as a scribe and writing the cues on the board.

- Joint board rewrite guided by the teacher, in which students replace the underlined cues with their own words, thus learning synonyms, paraphrasing and, most importantly, how to understand the text they are reading.

This is illustrated in Diagram 2 (Rose, 2005: 147): 


\section{Diagram 2: The R2L Six-Stage Teaching Cycle}

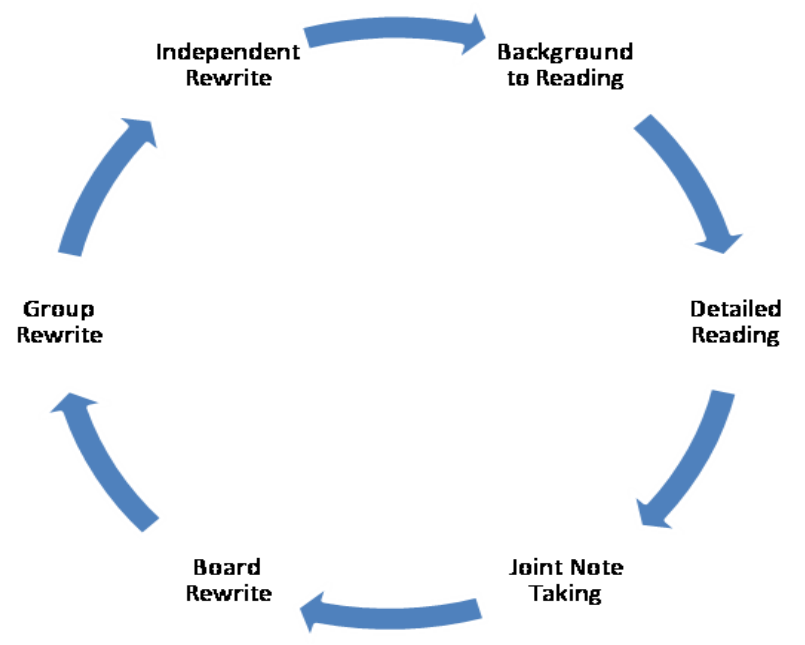

In this way, students are assisted in writing appropriate genres by the continued and parallel explicit teaching of reading, and weaker readers in a class can be assisted by this method to achieve new levels of literacy and thus begin to feel more in control of their learning.

\section{THE STUDY}

This study was divided into three stages in line with a Critical Action Research paradigm (Habermas, 1972, Kemmis and McTaggart, 2003). These stages consisted of: preintervention, intervention and post-intervention. Each stage is described in more detail below.

\section{PRE-INTERVENTION PHASE}

The pre-intervention phase comprised preparation for the implementation of the approach and consisted of a questionnaire on literacy history, an initial writing assessment task and initial reading level assessments.

The Literacy History Questionnaire contained both open and closed questions in order to obtain both qualitative and quantitative data (see Appendix 2). The purpose of the questionnaire was to ascertain the background of participants such as schools attended, their language background, and exposure to and experience with print. The open questions aimed to capture difficulties with reading in both English and home language.

An initial writing assessment task was given to the students in order to act as a baseline test for measuring the writing skills with which students had entered the programme. This task formed a short written response to a social comment from a newspaper (see Appendix 4). From the results of the initial writing task, a group of ten students were selected for tracking. This group was made up of three stronger, four average and three weaker students. 
Reading assessments were also used as a baseline by which to measure any later improvements in reading levels. Although other assessment tests and methods are available for measuring academic literacy and reading ability (Klapwijk, 2013, Van der Slik and Weideman, 2008, Van Dyk, 2004), these reading texts were selected from a series of graded texts provided for assessment in Rose (2009) which are graded from year 1 to year 10, with an additional text added by the researcher for years 11 to 12 . Although the readings for years 1 to 10 were graded according to the Australian education system, this did not cause complications since South African and Australian schools both start with a Kindergarten year at age 5 to 6 , followed by year 1 at age 6 to 7, through to year 12. The reading tests were conducted according to R2L guidelines which followed a set procedure. Students first read the text aloud to the lecturer. During this initial reading, the researcher recorded miscues, hesitations and mis-pronunciations. Then the total number of 'errors' was divided by the total number of words contained in the text as follows:

\section{Total Number of Errors $\div$ Total No. of Words Contained in the Text}

A score of 10 or less indicates that the student is reading at the given grade level. Thus, if a student achieves a score of 9 , that student falls just within the level of that reading grade. However, if a student achieves 11, for example, they are falling just outside of the acceptable reading level. The researcher then asked students both inferential and referential questions on the text to ascertain students' comprehension level. These questions differed according to the content of the text being read, as illustrated in an extract from Lockie Leonard Legend (Winton, 1997) below (see Appendix 5):

- Understanding of information that was explicitly contained in the text such as: 'What were the missiles that were shooting out of the water?'

- Understanding of information that was implicit in the text, such as: 'What were the feelings of the character, Lockie Leonard, about what he was experiencing?'

- Was the student able to relate in any way to what was happening in the text? For example, had the student ever seen a dolphin and how would s/he feel if s/he had a chance to watch dolphins play in the ocean?

If the answers given by the student indicate that $\mathrm{s} /$ he does not have a good comprehension of what has been read, then that student is assessed as reading at below the grade level of the particular text. The assessments were recorded and transcribed. The same set of graded reading texts were used in both pre- and post-reading assessments conducted in March and November 2011, respectively.

\section{INTERVENTION PHASE}

The intervention phase involved the teaching of five genres that were assessed by means of R2L criteria (see Appendix 1). These genres were taught over two semesters and consisted of a narrative, an explanatory text, an exposition, an editorial and an academic argument.

Each genre followed the R2L teaching cycle and took an average of two weeks to complete. In between the teaching of the genres, other classroom activities were engaged in, such as 
formal and informal debates and additional grammar exercises. These also served to provide a break between the teaching of genres and writing tasks.

The genres were taught according to the six-stage R2L teaching cycle mentioned above (see Diagram 2). At the end of each R2L cycle, the independent writing task formed the basis of the assignment that the students were given. In addition to the written genre tasks, the students also wrote one class test and one formal examination paper per semester. The same texts that had been taught to the students during the semester were used for assessment in both class-test and examination papers. The method used for teaching the genres is explained further below.

These genres differ in their purpose and intended audience and, therefore, in the way in which they are structured and the type of language used. Students need to learn the importance of the use of field, tenor and mode (see Table 2) in relation to informal and more formal discourses when writing texts. The genres that were taught during this research study could be roughly placed at different points on a line, as illustrated in Diagram 3:

\section{Diagram 3: Continuum from Spoken to Written Language}

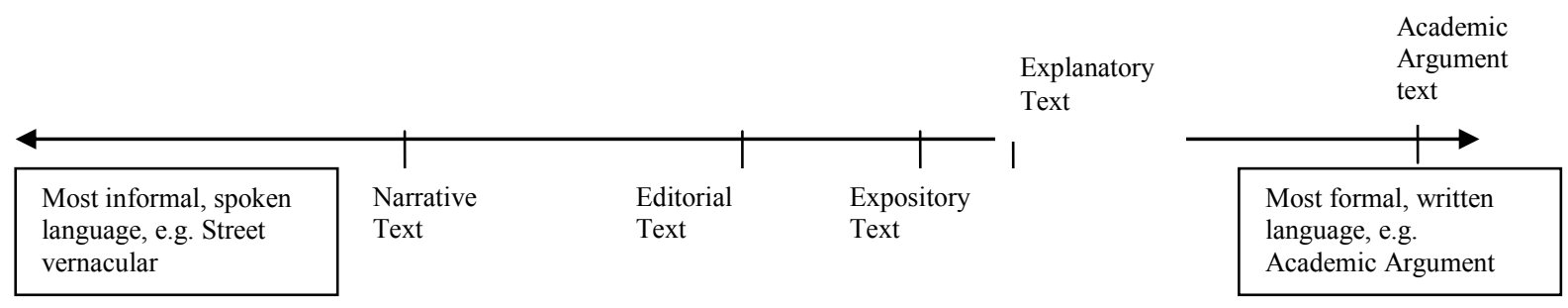

Although the continuum between spoken and written language as outlined in Diagram 3 could be regarded as simplistic, it helped the particular students experiencing the R2L intervention to understand the various genres and texts one is exposed to. Considering that the majority of the students participating in the study have had a lack of access to print throughout their formal schooling years, they tended to be unfamiliar with the formal written mode of language used for academic purposes (Cummins, 2000, Cope \& Kalantzis, 1993). How the teaching occurred within the R2L cycle is discussed below.

Each R2L cycle began with an explanation of the contextual and cultural background of a particular text. After the 'preparing for reading' stage, the process of detailed reading - stage two - followed. This involved selecting a particular stage of the text, explaining the stage and phases within it, and reading line by line with the students. The text was first read by the class as a whole, after which each sentence was paraphrased by the teacher. Students were assisted to locate important information in the text, which was then underlined.

Stage three of the cycle consisted of note-taking. Each student acted as a scribe by coming to the front of the classroom and writing the important information that was previously underlined during stage two, on the board. The seated students called out the words that needed to be written down to the scribe and corrected him/her if one of the words or phrases was misspelled. This stage assisted students with issues of punctuation, spelling and notetaking skills. 
Stage four consisted of a joint board-rewrite. Once again, students took turns acting as scribes and writing the sentences from the text on the board. However, this time the keywords were replaced by the students' own words. This helped to deconstruct the text, find the meaning of difficult terms and words, and deconstruct the meanings in nominalisations.

Whereas the board-rewrite meant replacing the keywords or notes with everyday meanings, in stage five the students were given back the original keywords and required to put them back together into a text resembling the original, thus reconstructing the text. Stage six consisted of an independent rewrite which meant that each student had to find another text of the same genre and, rewrite the text in his or her own words.

As each new genre was taught, the differences in purpose, audience and structure were made explicitly clear to the students. It was explained how the purpose and audience of a text determines the way information is structured, as well as the choices of words, field, tenor and mode made by the author.

The genre that the students had the most difficulty with was the Academic Argument. It is worth noting that critical thinking abilities are also regarded as an important component of academic literacy proficiency and that academic texts can be used to build skills in this area (Cattell, 2006). Due to the difficulty level of this genre, the lecturer used an idealised text that was written and simplified to facilitate learning. The text was taught in three sections corresponding to the three main stages of an academic genre: introduction, development of argument and conclusion.

Students experienced difficulty with the concept of providing main and sub-headings, numbering and conclusions. Some students still thought in terms of the middle of an essay being the 'body' and consisting of only one paragraph. They further had difficulty with the concept of 'nominalisation'. Within R2L, the term 'nominalisation' - the process of creating nouns out of other parts of speech (Halliday and Matthiessen, 2004) centres around the difficulty ESL/EFL students have in reading a text that is 'informationally dense'. The reason for this density is because a large amount of information is 'packaged' into nouns or noun phrases within the text. Academic texts generally contain more nominalisations than other genres. Students are assisted by the lecturer to both read and understand these nouns in texts by writing out their meaning in simpler, more accessible language.

As R2L is also concerned with the quality of classroom interaction, the researcher also observed the students in relation to class participation and attitudes towards the R2L approach during this intervention period. Students who are unable to read at the required levels for curriculum engagement are less likely to participate actively in classroom learning (Rose \& Martin, 2012). Therefore, it is important that the classroom discourse is designed in such a way as to support and encourage the active participation and learning of weaker students. In addition, informal discussions regarding the students' understanding and perceptions of what they were learning were held in class from time to time. All of the observations made by the researcher, as well as comments and feedback from the students (both solicited and unsolicited), were noted and recorded in the researcher's journal (see Appendix 6). 


\section{POST INTERVENTION PHASE}

The post-intervention phase consisted of a second set of reading assessments conducted with the tracked students, collation and analysis of recorded data, and comments from students and lecturers received after the end of the study period. Each of these processes is discussed in more detail below.

Reading assessment results were recorded and results for both semesters placed side by side for comparison (see Table 1). The same protocols were used as those in the pre-assessment readings, with sessions having been recorded and transcribed.

In addition to the quantitative data collected from the reading assessments, qualitative data was obtained from the interviews with participants, unsolicited comments from students and the journal entries mentioned above.

\section{FINDINGS}

Rose $(2011,2012)$ makes the claim that the R2L intervention increases reading levels from double to four times the standard rates in one year. Results from the reading assessments conducted in this study showed an increase of between one and six reading levels over the period of the research. In Table 1, below, reading levels are recorded for both pre-intervention and post-intervention assessments and placed side-by-side for comparison.

Table 1: Pre- and Post-intervention Reading Assessment Results

\begin{tabular}{|l|l|l|l|l|l|l|l|l|}
\hline & $\begin{array}{l}\text { Initial } \\
\text { reading } \\
\text { grade Level } \\
\text { on entering } \\
\text { University }\end{array}$ & Errors & $\begin{array}{l}\text { Word } \\
\text { No. }\end{array}$ & Score & $\begin{array}{l}\text { Reading } \\
\text { grade level } \\
\text { during 2 } \\
\text { assessment }\end{array}$ & Errors & Word No. & Score \\
\hline Andy & Grade 5 & 7 & 141 & 4.9 & Grade 6 & 16 & 203 & 7.8 \\
\hline Samantha & Grade 4 & 11 & 141 & 7.8 & Grade 6 & 21 & 202 & 10.3 \\
\hline Seth & Grade 3 & 13 & 122 & 10.6 & Grade 9 & 14 & 238 & 5.8 \\
\hline Zelda & Grade 5 & 10 & 141 & 7 & Grade 5 & 7 & 139 & 5.8 \\
\hline Gwyneth & Grade 5 & 12 & 141 & 8.5 & Grade 7 & 13 & 267 & 4.8 \\
\hline Michael & Grade 6 & 13 & 197 & 6.5 & Grade 7 & 8 & 267 & 2.9 \\
\hline Boniface & Grade 5 & 9 & 141 & 6.3 & Grade 8 & 12 & 186 & 6.4 \\
\hline Lannice & Grade 12 & 8 & 265 & 3 & Grade 12 & 2 & 275 & 0.7 \\
\hline Noleen & Grade 6 & 4 & 197 & 2 & Grade 10 & 3 & 240 & 1.25 \\
\hline
\end{tabular}

In the case of the first three listed students, Andy, Samantha and Seth, there was an increase of one, two and six reading grade levels respectively. These students initially were the weakest in the tracked group, with Seth entering the study at the lowest reading level (grade 3 ) of the total 46 participating students. It was this same student who showed the greatest increase of six levels. 
In two cases, those of Zelda and Lannice, there was no increase in reading levels per se. However, in both cases, the score for the grade level was lower, indicating some improvement in the 'error' margin. More importantly, comprehension increased for both students, particularly in the case of Lannice, who, although fluent in her reading of the initial grade 12 text, showed little comprehension of what was being read. However, when the assessment was repeated using the same text post-intervention, her comprehension had greatly improved as indicated in the table above, as the error score dropped from 3 to 0.7 .

Regarding the written tasks recorded for the tracked students, there was a general decrease in the formal assessment marks for 7 out of the 10 tracked students across the two semesters (see Appendix 1). This decrease ranged between 2 and $11 \%$ and is possibly due to the stress of exam conditions and increase in difficulty levels of the genres used between the first initial writing task and the final task. The final task was an academic essay - arguably the most difficult genre to write. The assessment criteria used for all written tasks comprised an R2L fourteen-point system that was selected because it is an R2L-specific assessment tool and forms an integral part of the overall approach. A recommendation could be made for a similar R2L intervention to be conducted using an assessment tool such as the Test of Academic Literacy Levels (TALL), which is not only used to measure initial literacy levels of students but also to measure possible improvement over time (Van der Slik and Weideman, 2008). The fourteen assessment criteria points used in this research are explained briefly in Table 2 .

\section{Table 2: Explanation of R2L Assessment Criteria}

\begin{tabular}{|l|l|}
\hline CONTEXT & How appropriate and well developed is the genre for the writing purposes? \\
\hline Purpose & $\begin{array}{l}\text { Does it go through appropriate stages and how well is each stage } \\
\text { developed? }\end{array}$ \\
\hline Staging & $\begin{array}{l}\text { How well does the writer understand and explain the field in factual texts, } \\
\text { construct the plot, settings and characters in stories, or describe the issue in } \\
\text { arguments? }\end{array}$ \\
\hline Field & $\begin{array}{l}\text { How well does the writer engage the reader in stories, persuade in } \\
\text { arguments or inform in factual texts? }\end{array}$ \\
\hline Tenor & Is the language appropriate in terms of written or spoken text? \\
\hline DISCOURSE & $\begin{array}{l}\text { Phases are the steps that a text goes through within each stage. A well- } \\
\text { organized text will have a logical sequence of steps. }\end{array}$ \\
\hline Phases & The word choices made by the writer to build the field of text. \\
\hline Lexis & The word choices writers use to make value judgments. \\
\hline Appraisal & The logical relations between sentences and within sentences. \\
\hline Conjunction & $\begin{array}{l}\text { The words (pronouns, articles, demonstratives) that are used to keep track } \\
\text { of people and things throughout a text. }\end{array}$ \\
\hline Referencing & Are the grammatical conventions of English used correctly? \\
\hline GRAMMAR & Are full stops, commas etc. used appropriately and correctly? \\
\hline GRAPHIC FEATURES & Are words spelled correctly, both frequent and less frequent? \\
\hline Punctuation & $\begin{array}{l}\text { Are paragraphs used? How legible is the writing? Is the layout clear? Are } \\
\text { required numbers and headings in place? }\end{array}$ \\
\hline Spelling &
\end{tabular}


All writing assessment scores were recorded and entered into a table for analysis (see Appendix 1). This analysis was conducted using a 'Repeated Measures Test' for Equality of Means (SAS Version 9.2). Detailed results showed a marked improvement in five criteria, both at the macro \& micro levels, as follows:

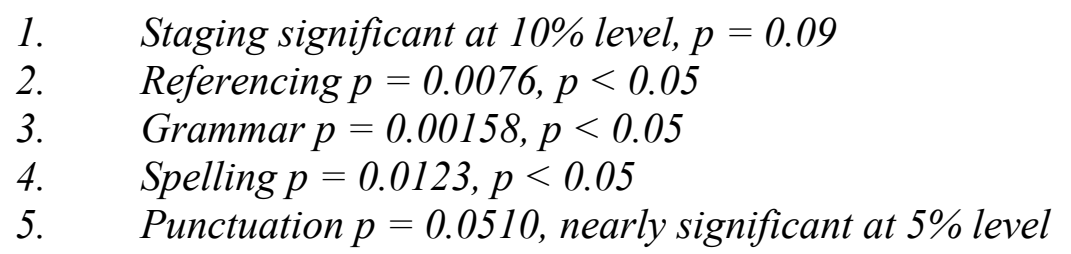

Although the improvements were noted in only five of the fourteen criteria, these five are quite significant in that they show improvement in both 'surface' and 'deeper' levels of text skills. It is possible that spelling and punctuation may be more easily taught to students, hence the reason for improvement at these micro levels. However, when dealing with issues at the macro level of text, such as staging and referencing, one is dealing with an understanding of how different texts structure information. This, in turn, relates to the 'hidden' conventions and expectations of society, which serve to keep students from access to economic power.

Referencing, which involves the use of logical connectors, referring articles and pronouns (items which link text to text and create both textual cohesion and comprehension), was a difficult concept for the students to grasp, and the researcher worked consistently on this area of text structure across the study period. Grammar was another area in which students struggled consistently, for example, in the use of articles in English, tenses, clauses and sentence construction. The unit of meaning within R2L is the clause, the rationale being that meaning is created not only through individual words but also through larger stretches of text. Improvement by the students in areas such as referencing and grammar are significant as they indicate a deeper level of comprehension of how texts are constructed to produce meaning.

It would be difficult to say which genres students did best in per se, as the difficulty levels of all texts increased during the study period. Items which stand out are the explanation text and the initial narrative. Areas of difficulty, however, were undoubtedly the editorial and the academic essay in the second semester. This may be a potential area for future research, i.e. an investigation of which of the fourteen criteria utilised by Rose (2009) are more operative with different genres.

\section{CONCLUSION}

It would appear that this study has gone some way towards validating the claims made by Rose $(2011,2012)$ that R2L can make a difference to the academic literacy levels of students at tertiary level. The correlation between early exposure to print and academic success has been clearly shown (Ntuli \& Pretorius, 2005). The students participating in this research project originated demographically from disadvantaged backgrounds where they had little or no access to print. This was evidenced by extremely weak academic literacy skills. The R2L approach claims to be able to increase reading levels between two and four levels within one year, and to be able to close the gap between stronger and weaker students (Rose, 2006, 
2011). In light of this, the approach was implemented to see if it could benefit students at tertiary level.

Implemented over a period of one year, the results of the approach indicated an increase of between one and six levels in reading skills and showed significant increases at both the macro and micro levels of academic writing ability. In addition, perceptions of participating students themselves, as well as other lecturers, indicated positive attitudes and perceived benefits of R2L. These comments and reflections, both solicited and unsolicited, indicate that the R2L skills are both transferable and sustainable. The good news for educators is that, despite the conditions surrounding South Africa's poor education system and the poor background of students, we do not have to accept a negative, self-fulfilling prophecy that perceives such students as headed for academic failure. On the contrary, R2L is an intervention that can overcome such limitations. The authors believe that, through the use of R2L strategies, a poor educational and economic background can cease to have major relevance for academic outcomes.

\section{REFERENCES}

BERNSTEIN, B. 1990. The structuring of pedagogic discourse: Volume IV of Class, Codes and Control. London: Routledge.

BERNSTEIN, B. 2000. Pedagogy, symbolic control and identity: theory, research, critique. Maryland: Rowman \& Littlefield.

BOUGHEY, C. 2008. Texts, practices and student learning: a view from the South. International Journal of Educational Research, 47(3):192-199.

BERNSTEIN, B. 1990. The structuring of pedagogic discourse: Volume IV of Class, Codes and Control, London, Routledge.

BRUNER, J. 1957. The relevance of education, New York, W W Norten.

CARSTENS, A. 2008. A multidirectional model for tertiary-level disciplinary writing. Journal for Language Teaching, 42, pp. 81-97.

CATTELL, K. 2006. Developing the language of argument: a bilingual approach. Southern African Linguistics and Applied Language Studies, 24, pp. 143-150.

CUMMINS, J. 2000. Putting language proficiency in its place: responding to critiques of the conversational/academic language distinction. In: CENOZ, J. \& JESSNER, U. (eds.) English in Europe: the Acquisition of a Third Language. Clevedon: Multilingual Matters.

HABERMAS, J. 1972. Knowledge \& human interests., London, Heineman.

HALLIDAY, M. \& MATTHIESSEN, C. 2004. An introduction to functional grammar, London, Arnold.

HALLIDAY, M. A. K. 1994. An introduction to functional grammar, London, Arnold.

HALLIDAY, M. A. K. 1995. A Recent View of "missteps" in Linguistic Theory. In: ELLIS, R. O. J. M. (ed.) Language, thought \& logic. Evanston, Ill.: Northwestern University Press. 
HOWIE, S., VAN STADEN, S., TSHELE, M., DOWSE, C. \& ZIMMERMAN, L. 2012. PIRLS 2011: South African children's reading literacy achievement report. Pretoria: University of Pretoria.

JANSEN, J. 1998. Curriculum reform in South Africa: a critical analysis of outcomes based education (1). Cambridge Journal of Education, 28, pp. 321-332.

KEMMIS \& MCTAGGART 2003. Participatory action research. In: DENZIN \& LINCOLN (eds.) Strategies of Qualitative Enquiry. Thousand Oaks, C.A.: Sage Publications.

KLAPWIJK, N. 2013. Cloze tests and word reading tests: enabling teachers to measure learners' reading-related abilities. Per Linguam, 29, pp. 49-62.

KLOS, M. 2011. Genre pedagogy in the mediation of socially-situated literacies acquisition the experience of apprentices in a higher education community of practice. Journal for Language Teaching, 45, pp. 132-151.

MACHET, M. P. \& PRETORIUS, E. J. 2008. The impact of storybook reading on emergent literacy: Evidence from poor rural areas in KwaZulu-Natal, South Africa. Mousaion Special Issue, pp. 261-289.

MARTIN, J. R. \& ROSE, D. 2005. Designing literacy pedagogy: scaffolding democracy in the classroom. In: WEBSTER, J., MATTHIESSEN, C. \& HASAN, R. (eds.) Continuing discourse on language. London: Continuum.

NTULI \& PRETORIUS, E. J. 2005.

ROSE, D. 2006. A reading based model of schooling. Pesquisas em Discurso Pedagógico, 4, pp: $1-17$.

VAN DER SLIK, F. \& WEIDEMAN, A. 2008. Measures of improvement in academic literacy. South African Linguistics and Applied Language Studies, 263, pp. 363-378.

VAN DYK, T. 2004. Switching constructs: on the selection of an appropriate blueprint for academic literacy assessment. Spaan Fellow: Working Papers in Second or Foreign Language Assessment, 2, pp. 135-155.

VYGOTSKY, L. S. 1978. Mind in Society: The Development of Higher Psychological Processes, Cambridge, M.A., Harvard.

WINTON, T. 1997. Lockie Leonard legend. Sydney: Pan.

\section{BIOGRAPHICAL NOTES}

Rosemary Wildsmith-Cromarty is Professor of Applied Language Studies in the School of Arts, University of KwaZulu-Natal. She has published widely on multilingualism, reading and the development and promotion of African languages. She is a member of the English National Language Body and KwaZulu-Natal Provincial Language Committee. E-mail address: wildsmithr@ukzn.ac.za

Kellie Steinke is a lecturer in English Language Development in the School of Arts, University of KwaZulu-Natal. She holds an MA degree in Applied Language Studies and has a strong interest in the application of the 'Read to Learn' pedagogy at tertiary level. 


\section{APPENDICES}

Appendix 1: Example of Detailed Assessment Criteria for Writing Tasks and Recorded Scores for Tracked Students

\begin{tabular}{|l|l|l|l|l|l|l|l|l|}
\hline & & & & & & & & \\
Task & Purpose & Staging & Field & Tenor & Mode & Phases & Lexis & Appraisal \\
\hline Initial Task & 5 & 3 & 3 & 4 & 4 & 2 & 3 & 2 \\
\hline $\begin{array}{l}\text { Explanation } \\
\text { Text }\end{array}$ & 3 & 3 & 3 & 2 & 2 & 3 & 2 & 3 \\
\hline
\end{tabular}

\begin{tabular}{|c|c|c|c|c|c|c|}
\hline Task & Conjunction & Referencing & Grammar & Spelling & Punctuation & Presentation \\
\hline Initial Task & 3 & 0 & 2 & 2 & 1 & 2 \\
\hline $\begin{array}{l}\text { Explanation } \\
\text { Text }\end{array}$ & 2 & 1 & 1 & 4 & 2 & 3 \\
\hline
\end{tabular}

\section{Appendix 2: Selected Questions from Literacy History Questionnaire}

1. Did anyone read to you before you started school?

2. If so, when?

3. What did they read to you?

4. How many times did you get a copy of your own text to read during school?

5. Did you read for entertainment at school?

6. If so, what did you read?

7. Did your primary or high school have a functioning library?

8. Did you use a public library?

9. Do you read now for entertainment?

10. If so, what do you read?

11. Do you read internet articles?

12. Do you find reading English difficult? If so, say why.

13. Do you find reading in your home language difficult? If so, say why.

14. Do you read in any language other than English? If so, say which language/s.

15. Did either your Primary or High school have a library with books that students were allowed to read?

16. Do you find reading English difficult? If so, say why. 


\section{Appendix 3: An Example of R2L Cycle Stage 2: Detailed Reading}

Extract from "Good Tip for Ghosts" (Jennings, 1995)

\begin{tabular}{|l|l|}
\hline How far & Where from \\
\hline
\end{tabular}

1. A little way off behind some old rusting car bodies, I thought I heard a noise.

Same way $\quad$ How scared

2. Pete was looking in the same direction. 3. I was too terrified to move.

\begin{tabular}{|l|l|}
\hline Tried to get away & Tried to yell \\
\hline
\end{tabular}

4. I wanted to run but my legs just wouldn't work. 5. I opened my mouth to scream

Couldn't scream

Feet wouldn't move

but nothing came out. 6 . Pete stood staring as if he was bolted to the ground.

1. This is the part where the boys are at the dump. They think no one else is there but then they hear a noise.

- how would the boys be feeling?

2. what Pete was doing?

- why would Pete be looking in the same direction? Must have been a noise.

3. how the boy was feeling, how scared he was.

- what are the things we want to do when we are really scared? Run and scream.

4. exactly how he couldn't run.

- so scared he couldn't make his legs move.

5. he wanted to scream but couldn't.

- discuss how both sentences have the same pattern - to emphasise the feeling.

6. Pete couldn't move either. 


\section{Appendix 4: Initial Writing Task}

WRITING TASK: 07/02/2011

The following text comes from an SMS sent to the editor of the Times Newspaper, in which a reader expresses her views about whether or not the upcoming Municipal vote will make a difference to the people of South Africa:

'I only believe my vote makes a difference for the politicians and not for the people of South Africa. After voting them into power, they become the 'untouchables' through their lavish lifestyles and corruption.' - MaNdlovu

The Times Newspaper. Your SMS Comments. Tuesday February 1, 2011, p. 17.

Think about the above SMS, and then write $10-15$ lines on whether you agree or disagree with MaNdlovu's comment. 


\section{Appendix 5: Grade 5 \& 6 Texts used for Reading Assessment (Winton, 1997).}

\section{Fins}

Thkie Leonard shook the spray from his eyes, In adjusted himself on the board and kept padding as the wave rolled past and collapsed with a buntingling thud on the sandbar. Out of the cool mist another swell rose all seething and nutley-green and shot six glistering, giggling nissiles into the sky. They twisted in the air and cane spearing straight at him. Lockie stopped padding and stared. As any halfwit knows, of course, this is not such a smart thing to do when a big hotrie wave 1 s bearing down on you like a cement truck. But the human torpedo couldit help himself. Dolphins! Alright?

He watched them stall and turn in perfect formation, cutting white slices through the skin of the water, curving back bn themselves the w* io human surfer could even hope to. They 


\section{Appendix 6: Selected Notes from Researcher's Personal Journal}

\section{Entry: $25^{\text {th }}$ March 2011}

Some interesting observations from my preliminary reading assessments:

It seems that several of the students can read a text fluently, barely without a hesitation or a mispronunciation - but can't understand a thing of what they've read! This includes academic texts (where the learner was at a level to attempt one)!

\section{Entry: $5^{\text {th }}$ May 2011}

I gave the learners the writing task this week. They have to find a business or economics article that is in the same genre as the one we've been working on - i.e. explanatory text.

I offered several example texts for the weaker students. The idea is that they take the content (through use of highlighting keywords) and then re-write in their own words.

What I feel is interesting is that the stronger students took a keen interest in finding their own texts - even taking a newspaper report and seeing if they can rewrite it as an explanation, whilst the weaker ones gratefully gravitated towards the examples.

This could be a way in which stronger learners aren't left behind in that they can be stretched. What seems common to all is that they all feel they can do this - in fact, they are surprised when they find out how 'easy' it is! Of course, their writing at this stage (as evidenced from my initial samples) is appalling! So they hopefully are going to learn without completely realizing that they have to??

\section{Entry: May $14^{\text {th }}$}

Had several students come up after lectures now and tell me that R2L is working. S. Came up quietly to me today. Said it has helped in Economics test.

\section{Entry: $7^{\text {th }}$ November 2011}

There were some encouraging comments today from one of the BCom Economics lecturers. He teaches upstairs, not in the basement, and I have not met him before.

However, he was saying to P. that the 1st year BCom4 students seemed to both write and understand the questions better than the 2nd years, and that he was surprised by this. He thought it was because they were "getting more English".

P. explained the new R2L methods that we're using and he was impressed.

It's good to get some encouragement from an objective source! 